Nigerian Journal of Physiological Sciences 24 (2): 91 - 94 @Physiological Society of Nigeria, 2009

Available online/abstracted at http://www.bioline.org.br/np; www.ajol.info/journals.njps; www.cas.org

\title{
EPIDEMIOLOGY AND CLINICAL FEATURES OF ACUTE GLOMERULONEPHRITIS IN CALABAR, NIGERIA
}

\author{
I. S. ETUK, M. U. ANAH AND M. E. EYONG \\ Department of Paediatrics, College of Medical Sciences, University of Calabar, Calabar, Nigeria \\ E-mail: etukimaobong@yahoo.com Tel +234802 788521
}

\begin{abstract}
Summary: A retrospective study of children with acute glomerulonephritis (AGN) over a 10-year period (January 1997-December 2006) was carried out with the aim to establish the prevalence, the population at risk, and the predisposing factors. Out of a total of 6,026 admissions during the study period, 76 (1.3\%) had acute glomerulonephritis. Forty of the 76 were males while 28 were females with a male to female ratio of 1.4:1. The mean age for males was $7.2 \pm 4.3$ years and that of females was $6.5 \pm 3.2$ years. The overall age range was 3-13 years with a modal age of 5 years for both sexes. The annual prevalence showed two peaks, May-July and October-January. Eighty two percent of patients were of the low while $11.8 \%$ were of the middle socioeconomic classes. Haematuria, oedema, proteinuria and hypertension were the major presenting features. Hypertensive encephalopathy and acute renal failure were the complications recorded and also emerged as the causes of death. Childhood AGN is common in Calabar compared to other centres in Nigeria, afflicting largely those of low socio-economic status and displays a peak in the middle of both dry and rainy seasons of the year. The outcome is good but could be better if facilities are provided for dialysis.
\end{abstract}

Key words: Glomerulonephritis, prevalence, children, patients

\section{Introduction}

Acute glomerulonephritis (AGN) is one of the oldest and most common non-suppurative renal disease in childhood in the tropics and sub-tropic (Rodriguez-Iturbe and James 2008; Travis 1978). It remains the leading renal cause of childhood morbidity in the developing countries in contrast to the observed marked decline in its incidence in the rest of the world (Bello 1991; Eke and Nte, 1994; Meadow, 1975; Etuk et al, 2006). In most centres in Nigeria, it is the commonest cause of renal morbidity in children (Eke and Nte, 1994; Etuk et al, 2006; Okafor et al, 1995; Akhionbare and Abdulrahman, 1984; Hendrickse and Gilles, 1963; Hutt and White, 1964). AGN is a major cause of childhood hypertension with its complications.

The epidemiology and clinical features of AGN tend to vary with place and time within Africa (Travis1978; Etuk et al, 2006). For instance, reports from Enugu (Okafor et al, 1995), Port Harcourt (Eke and Nte, 1994), and Zaria (Akhionbare and Abdulrahman, 1984) have indicated increasing yearly incidence of this condition as against earlier reports from Ibadan and other parts of the world (Meadow 1975; Etuk et al 2006; Antia, 1995). In most parts of the developing world, including Nigeria, paediatric cases of AGN is largely associated with streptococcal infection of the throat and skin, a situation closely linked to low socio-economic status and poor environmental hygiene (Bello, 1991).

To our knowledge, the pattern of AGN in South-eastern Nigeria has not yet been documented, hence this study was carried out between January1997 and December 2006 to establish its clinical pattern, prevalence, population at risk, predisposing factors and highlight its seasonal variations among the childhood population seen in the University of Calabar Teaching Hospital(UCTH), Calabar, South-eastern Nigeria.

\section{Materials and Methods}

Using the ward admission register, and patients' case files, all children with the diagnosis of acute glomerulonephritis admitted into the UCTH from January 1997 through December 2006, were reviewed. The data abstracted from these records included: age, sex, date of admission of the children and the occupational and educational levels of parents. Other details included, presenting complaints with duration, history of throat and skin infections, blood pressure readings and body weight. The laboratory reports of interest were urinalysis, urine microscopy, urea, electrolyte and creatinine. Diagnosis was made using clinical features and relevant laboratory results. Renal biopsies were however not done. The duration of stay in hospital, outcome, and the total number of admissions and mortalities within the period were also noted. The limitation to this study arose due to missing case records, resulting from movement of the hospital to its permanent site.

The data obtained were analysed using simple percentages and differences in mean ages using student $\mathrm{t}$ - test. $\mathrm{P}$ value less than 0.05 was considered statistically significant. 


\section{Results}

During the 10 -year period under review, there was a total of 6,026 admissions of which $76(1.3 \%)$ were confirmed as having acute glomerulonephritis. Of the 76 children, only 68 case files could be retrieved, and these form the material for subsequent analysis.

These were $40(58.8 \%)$ males and $28(41.2 \%)$ were female with a male to female ratio of 1.4:1. Age range for males was 3-15 years with a mean age of $7.2 \pm 4.3$ years. Age range for females was $2.5-14$ years with a mean age of $6.5 \pm 3.2$ years, $t=$ $0.32, \mathrm{p}>0.05$. This was not statistically significant. The modal age for both sexes was 5 years.

Sixty patients $(88.2 \%)$ were of low socioeconomic classes (IV and V), while 8 (11.8\%) were of the middle social class III (Olusanya et al, 1985).

Table 1: clinical Features of 68 Patients with AGN

\begin{tabular}{ccc}
\hline Clinical Features & No & $\begin{array}{c}\text { Percentage } \\
(\%)\end{array}$ \\
\hline Haematuria & 68 & 100 \\
Proteinuria & 68 & 100 \\
Fever & 30 & 44 \\
Oliguria & 57 & 83.4 \\
Anuria & 4 & 5.9 \\
Dark Coloured Urine & 58 & 85.3 \\
Oedema & 67 & 98.5 \\
Ascites & 20 & 29.4 \\
Hypertension & 59 & 86.8 \\
Headache & 40 & 58.8 \\
Seizure/coma & 3 & 4.4 \\
Red Blood Cell Cast & 40 & 58.8 \\
Granula cast & 32 & 47.1 \\
Elevated Serum Urea & 12 & 17.6 \\
Elevated Creatinine & 9 & 13.2 \\
\hline
\end{tabular}

The average monthly and yearly incidence of AGN in the 68 subjects is as shown in Figures 1 and 11 respectively. The monthly average prevalence over the years have demonstrated two peaks May-July and October-January. The admission frequencies were evenly distributed throughout the period of study with an average of 5-8 cases seen yearly.

The clinical features are as shown in Table 1. All of the 68 children had haematuria and proteinuria; sore throat was documented in $14.7 \%$ of cases and skin infection in $22.1 \%$. Others were oliguria $(83.4 \%)$, dark coloured urine $(85.5 \%)$ oedema $(98.5 \%)$ and hypertension $(86.8 \%)$. Complications recorded were acute renal failure 4 patients $(5.9 \%)$, hypertensive encephalopathy, 3 $(4.4 \%)$ and congestive cardiac failure, $2(2.9 \%)$.

Five of the 68 patients left the hospital against medical advice, 2 were referred to centres with facilities for dialysis. Of the 61 remaining patients, 3 died giving a case fatality rate of $5 \%$. The causes of death were cardiac failure and hypertensive encephalopathy. Of the 300 children who died in the ward within the period, 3 or $1 \%$ were due to AGN.



Fig. 1: Graph showing the monthly incidence of $A G N$ in 68 subjects

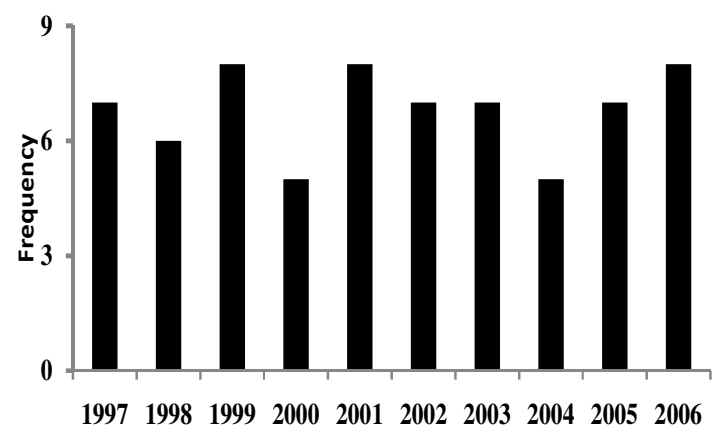

Fig. 2: Graph showing yearly distribution of AGN in 68 patients

\section{Discussion}

A prevalence rate of $1.3 \%$ obtained for acute glomerulonephritis over a 10 -year period in this study has demonstrated that this condition is not uncommon in Calabar. It is most likely that a community survey could have produced a more reliable figure. Nevertheless, this is higher than the $0.8 \%$ obtained in Benin City (Ibadin and Abiodun, 2003) but lower than the figures from the USA (Travis, 1978), Enugu (Okafor et al, 1995) and Zaria (Akhionbare and Abdulrahman, 1984) The male preponderance in the present study is in consonance with the observation of other authors (Bello 1991; Eke and Nte, 1994; Antia 1995; 
Glomerulonephritis, epidemiology in Calabar, Nigeria

Okafor et al, 1995; Akhionbare and Abdulrahman, 1984; Ibadin and Abiodun, 2003). There appears to be a sustained prevalence of 5-8 new cases per year which is consonant with reports from Port Harcourt (Eke and Nte, 1994) and Western Nigeria (Hendrickse and Gilles, 1984) but lower than the annual prevalence of $31-50$ obtained in other Nigerian centres (Bello 1991; Okafor et al, 1995; Akhionbare and Abdulrahman, 1984). In developed countries with high socio-economic standard of living, there are reports of a declining incidence of AGN (Meadow 1975; Roys and Stapelton, 1990).

A double peak incidences per year is at par with the experience in Enugu (Okafor et al, 1995), and Zaria (Akhionbare and Abdulrahman, 1984), and Port Harcourt (Eke and Nte, 1994) but contrasts with the single yearly peak prevalence noted in Benin City (Ibadin and Abiodun, 2003). The two peaks observed fit into the dry and rainy seasons in Nigeria. Calabar City has extremes of weather condition; the rainy season is known to be quite wet with heavy occurrences of streptococcal throat infection and the dry season quite humid with high incidence of pyoderma. Streptococcal throat infection and pyoderma have been implicated as causal factors in AGN (Bello 1991; Eke and Nte, 1994; Akhionbare and Abdulrahman, 1984). These have served as portal of entry for the related bacteria. The documented rates of antecedent throat and skin infections were rather low $(14.7 \%$ and $21.2 \%$, respectively), compared to other studies by Okafor et al, 1995; Akhionbare and Abdulrahman, 1984; Ibadin and Abiodun, 2003). Being a retrospective study, it depended on the records which are most of the time poor in our environment. A prospective study is therefore needed to establish a correlation between throat and skin infections within the wet and dry seasons, respectively.

AGN has been described as a disease associated with poverty and low socio-economic status (Bello 1991; Eke, 1994). Our survey has confirmed this assertion in that $88 \%$ of the subjects in the study were of the lower social classes IV and V families. The present study confirms that haematuria and proteinuria are constant features in AGN patients. An African child with AGN is more likely to present acutely with generalised oedema of varying degrees accompanied by hypertension and proteinuria (Eke and Nte, 1994; Akhionbare and Abdulrahman, 1984; Ibadin and Abiodun, 2003). Oedema $(98.5 \%)$ and hypertension $(86.8 \%)$ were quite prominent a feature in this study. The frequency of hypertension obtained in the present study agrees with $82.5 \%$ in Benin City, but higher than the range of $45 \%-68 \%$ recorded in other centres within and outside Nigeria (Eke and Nte, 1994; Okafor et al, 1995, Akhionbare and Abdulrahman, 1984; Hutt et al, 1964).
It is of interest to note that in spite of the high incidence of hypertension among the present series, hypertensive encephalopathy was encountered in only $4.4 \%$ of the cases analysed. This mimics the experiences obtained in Benin City $(4.8 \%)$ and in Zaria (2\%), but contrasts with $11.6 \%$ noted in Enugu. Most authors appear to be silent over acute renal failure which is a known outcome of acute nephritis; in our series there were $5.9 \%$ of cases.

That $85 \%$ of the patients recovered from the AGN in this series is the good prognostic experience the world over. A case fatality rate of $5 \%$ was recorded. The fatality rate could probably have been lower if facilities for dialysing were available in the institution. It is a known fact that early initiative of dialysis improved the outcome of acute renal failure. This rate of 5\% agrees with figures obtained by Bello (1991) and Ibadin and Abiodun, (2003) but much higher than $1.4 \%$ and $1.5 \%$ reported from Enugu and Port Harcourt by Eke and Nte (1994) and Okafor et al (1995) respectively where dialysis can be administered.

This study has shown that acute glomerulonephritis is not uncommon in our environment, and is a disease of the low socioeconomic class. It has annual double peak prevalence. In agreement with international experience, it carries a good outcome but control measures are still necessary and there is need to provide facilities for dialysis to salvage cases complicated with renal failure.

\section{Acknowledgement}

We acknowledge with gratitude the effort of the record staff of U.C.T.H in retrieving the case folders of these patients and to Professor A.A. Asindi for painstakingly reading through the manuscript.

\section{References}

Akhionbare, H. A, Abdulrahman, M. B. (1984). Acute glomerulonephritis in Zaria. Nig. J. Paediatr. 11: 59-62.

Antai, A. U. (1995). Acute post-streptococcal glomerulonephritis: A common renal disease. Nig. J. Paediatr.22: 1-2.

Bello, A. B. (1991). A review of acute glomerulonephritis in children at Ilorin. Nig Med. Pract.21: 3-5.

Eke, F. U. and Nte, A. (1994). Prevalence of acute post streptococcal glomerulonephritis in Port Harcourt, Nig. J. Paediatr. 21: 32-36.

Etuk, I. S., Anah, M. U., Ochigbo, S. O. and Eyong M. (2006). Pattern of paediatric renal disorders in Calabar, Nigeria. Mary Slessor J.Med. 6: 30-34.

Hendrickse, R. G. and Gilles, H. M. (1963). The Nephritic syndrome and other renal diseases in children in Western Nigeria. East Afr Med. J. 40: 186-92. 
Hutt, M. S. R. and White, R. H. R. (1964). Clinicopathological study of acute glomerulonephritis in East African children. Arch Dis Child. 39: 313-323.

Ibadin, O. M. and Abiodun, P. O. (2003). Childhood acute glomerulonephritis in Benin City. Nig. J. Paediatr. 30:45-49.

Meadow, S. R. (1975). Post streptococcal nephritis: A rate disease? Arch Dis Child.50: 39-82.

Okafor, H. U., Okoro. R. A. I. and Ugwu, G. I. (1995). Acute glomerulonephritis in Enugu. Nig. J. Paediatr. 22: 31-35.

Olusanya, O., Okpere, E. and Ezimokhai, M. (1985). The importance of social class in voluntary fertility control in a developing country. West Afr J Med.4: 205-211.
Rodriguez-Iturbe, B. and James, M. M. (2008). The current state of post streptococcal Glomerulonephritis. J. Am. Soc. Nephrol. doi 10-1681/Asn.2008010092.

Roys, I. I. I. and Stapelton, R. B. (1990). Changing perspectives in children hospitalised with post streptococcal acute glomerulonephritis. Pediatr Nephrol. 4: 585-588.

Travis, L. B. (1978). Acute post-infectious glomerulonephritis. In: Edelman JCM, ed., Peadiatric Kidney Diseases. Boston: Little Brown and Co. (Publishers), 611- 631.

Received: June 26, 2009

Accepted: August 3, 2009 